\title{
Serum Calcium Level in Patients with Pre Eclampsia : A Case Control Study
}

Rajasree Bhowmick ${ }^{1 *}$

Juthi Bhowmik ${ }^{2}$

Shiuly Chowdhury ${ }^{2}$

Ayesha Najma Nur ${ }^{1}$

Firoza Begum ${ }^{3}$

\footnotetext{
${ }^{1}$ Department of Obstetrics \& Gynaecology Center for Women and Child Health Dhaka, Bangladesh.

${ }^{2}$ Department of Obstetrics \& Gynaecology Bangladesh Institute of Health \& Science Dhaka, Bangladesh.

${ }^{3}$ Department of Fetomaternal Medicine Bangabandhu Sheikh Mujib Medical University Dhaka, Bangladesh.
}

\begin{abstract}
Background: To compare serum calcium level in pre-eclamptic women and normal pregnant women.
\end{abstract}

Materials and methods: It was a case-control study carried out in patient Department of Fetomaternal Medicine unit in the Department of Obstetrics \& Gynaecology of Bangabandhu Sheikh Mujib Medical University (BSMMU), Dhaka. From September 2010 to February 2011. Total 60 cases, among them 30 comprising control group and 30 were cases. This was a non interventional case control study that was carried out on total 60 women with age range 18 to 38 years of them 30 healthy gravid women as control group and 30 pregnancy with pre eclampsia as case. Serum calcium level of the groups were measured, and compare between this two group. Data were analyzed by computer with the help of SPSS (Statistical Package for Social Sciences) win 13 software package.

Results: Serum calcium in pre-eclamptic women was significantly low [7.88 $\pm 0.75 \mathrm{mg} / \mathrm{dl}$ vs $9.9267 \pm 0.58 \mathrm{mg} / \mathrm{dl}]$ than in normal pregnant women.

Conclusion: Serum calcium may be used for earlier detection of preeclampsia. Further studies are required to investigate whether calcium supplementation can be used as a preventable measure for the development of preeclampsia.

Key words: Pre-eclampsia; serum calcium; Normal pregnancy.

\section{INTRODUCTION}

Hypertensive disorders of pregnancy are responsible for significant maternal and perinatal morbidity and are the second leading cause, after embolism, of maternal mortality in United States ${ }^{1}$. Preeclampsia is defined as the development of hypertension, proteinuria, or both, after 20 weeks of gestation in a previously normotensive women ${ }^{1}$. It affects 5 to $10 \%$ of all pregnancies yearly in USA ${ }^{2-6}$. In India incidence is recorded $5-15 \%$. The incidence in primigravida is about $10 \%$ and multigravida $5 \%{ }^{7}$. Incidence of pre-eclampsia in our country is still very high and the most common medical disorder that occur during pregnancy ${ }^{8}$. Inspite of different preventive approaches to improve obstetric care in Bangladesh it constitute about $5 \%$ of total deliveries and $16 \%$ of the maternal mortality which is equivalent of about 4500 women/Year'.

On the pathological basis, calcium plays an important role in muscle contraction and regulation of water balance in cells. Modification of plasma calcium concentration leads to the alteration of the blood pressure. The lowering of serum calcium and the increase of intracellular calcium can cause an elevation of blood pressure in preeclamptic mother. The explanation for this process is not clear. The low level of maternal total calcium is due to an increase in the fetal calcium demand, and is due to an increase in maternal estrogen production which blocks bone resorption which increase calcium excretion in urine and thus aggravates the situation ${ }^{10-11}$. 
Considering the above facts, the study will be carried out to analyze the serum calcium level in pre-eclampsia as well as in healthy pregnant normotensive women in the third trimester. It has been widely documented that there is relationship between low calcium level and pre-eclampsia. The low level of maternal total calcium may have a role in development of this disorder in pregnancy. Therefore calcium supplimentation during pregnancy may be used to help prevention of pre-eclampsia. However, till to date there is no evidence regarding this supplimentation and there are no available reports conclusively demonstrating the actual mechanism of pre-eclampsia.

\section{MATERIALS AND METHOD}

It was a case-control study carried out in patient Department of Fetomaternal Medicine unit in the Department of Obstetrics \& Gynaecology of Bangabandhu Sheikh Mujib Medical University (BSMMU) Dhaka. From September 2010 to February 2011. Study population consisting normal pregnancy at third trimester as control group, and pregnancy with pre-eclampsia at third trimester as case. Total 60 cases, among them 30 comprising control group and 30 were cases. This was a non interventional case control study that was carried out on total 60 women with age range 18 to 38 years of them 30 healthy gravid women as control group and 30 pregnancy with pre eclampsia as case. Serum calcium level of the groups were measured, and compare between this two group. After taking aseptic precaution, five milliliter of venous blood was collected at any time from each of pre-eclamptic patient as well as from control subjects, with a disposable syringe, by venipuncture, taking aseptic precaution. Blood collection was not related with food taking. From both group blood sample was collected during antenatal period following admission. The collected blood samples were allowed to clot and serum was separated by centrifugation at $3000 \mathrm{rpm}$ for 5-10 minutes. Then serum calcium level was measured by auto analyzer machine named PENTRA 400. Data were analyzed by computer with the help of SPSS (Statistical Package for Social Sciences) win 13 software package. Statistical analyses were done by using appropriate procedure like chi square test, student t-test where applicable. Statistical significance is set at 0.001 level, confidence interval at $95 \%$ level.

\section{RESULTS}

This case control study was conducted on pregnant women who had pre-eclampsia and pregnant women who were normotensive and admitted in inpatient department of Fetomaternal Medicine unit of Department of Obstetrics \& Gynaecology of BSMMU from September 2010 to February 2011. Total 60 patients were selected among them 30 were cases (Preeclamptic women) and 30 were selected as control (Normotensive pregnant women). The result of this study is mentioned below:

Table I : Age of the respondents.

$\begin{array}{llrrr}\text { Group } & \mathbf{n} & \begin{array}{r}\text { Range } \\ \text { Mean } \pm \text { SD }\end{array} & \text { p value }^{\text {a }} \\ \text { Case } & 30 & 18.0-35.0 & 27.30 \pm 4.284 & \\ & & & 27.33 \pm 4.581 & >0 . .489^{\text {ns }}\end{array}$

Control $\quad 30 \quad 19.0-42.0$

Case-Preeclamptic women, Control-normotensive pregnant women, ns-non significant, n-total number of respondent, a- $\mathrm{p}$. value is reached from chi square.
Table II : Gestational age.

\begin{tabular}{lrrr}
\multicolumn{2}{l}{ Gestational age Case (n -30) } & Control (n -30) & p value \\
No (\%) & No (\%) & \\
Preterm & $21(70)$ & $7(23.3)$ & \\
Term & $9(30)$ & $23(76.7)$ & $0.000^{\mathrm{s}}$ \\
\hline
\end{tabular}

Case--Preeclamptic Women, Control-- Normotensive Women.

Table III : Distribution of Gravida.

\begin{tabular}{llll} 
& $\begin{array}{l}\text { Prime } \\
\text { n (\%) }\end{array}$ & $\begin{array}{l}\text { Multi } \\
\mathbf{n}(\%)\end{array}$ & p value a \\
Case(n-30) & $13(43.3)$ & $17(56.7)$ & \\
Control (n-30) & $11(36.7)$ & $19(63.3)$ & $>0.598^{\text {ns }}$ \\
\hline
\end{tabular}

Case - pre eclamptic women, Control - Normotensive pregnant women.

Table IV : Distribution of BP level.

\begin{tabular}{lrrrr} 
Group & n & \multicolumn{1}{c}{ Range } & mean + SD & p value $^{\text {a }}$ \\
Systolic BP & & & & \\
Case & 30 & $120-180$ & $129.33+22.31$ & \\
Control & 30 & $90-120$ & $110.33+9.64$ & $<0.001^{\text {s }}$ \\
Diastolic BP & & & & \\
Case & 30 & $80-125$ & $87.42+17.11$ & \\
Control & 30 & $60-80$ & $72.33+6.66$ & $<0.00^{\text {s }}$ \\
\hline
\end{tabular}

Case -- Pre eclamptic women, Control -- Normotensive pregnant women, a-- t test, $\mathrm{s}$ - Significant.

Table V : Serum calcium level.

\begin{tabular}{lcrrr} 
& n & \multicolumn{1}{c}{ Range } & mean + SD & p value $^{\mathrm{a}}$ \\
Case & 30 & $6.80-9.10$ & $7.88+0.75$ & $5.25 \mathrm{E}-14^{\mathrm{s}}$ \\
Control & 30 & $8.80-11.10$ & $9.9267+0.58$ & \\
\hline
\end{tabular}

Case - Pre eclamptic women, Control - Normotensive pregnant women, $\mathrm{n}$ - total number of patient, a-- $\mathrm{t}$ test, $\mathrm{s}$-- significant

\section{DISCUSSION}

This case control observational study was carried out with an aim to compare serum calcium level between preeclamptic (Case) and normotensive (control) women. And also to compare socio demographic variation between two groups. A total 60 women between 28 to 40 weeks of gestation among them 30 were preeclamptic (Cases) and 30 were normotensive (Control) included in this study, in Fetomaternal Medicine unit of the Department of Obstetrics and Gynaecology of BSMMU during September 2010 to February 2011.The present study findings were discussed and compared with previously published relevant studies.

In this study it was observed that mean $( \pm \mathrm{SD})$ age of the case was $27.30 \pm 4.284$ years and in control group $27.33 \pm 4.581$ years. Mean age was not significant $(\mathrm{p}>0.489)$ between case and control group (Table-I). This finding is consistent with the study of Duekilt \& Harington, in which they found young maternal age did not seem to affect the risk of developing preeclampsia ${ }^{12}$. 
Regarding gestational age, both case and control group ranged from 28 to 40 weeks, where preterm $(<37$ weeks) were found $21(70 \%)$ in case and $7(23 \%)$ in control group, where as in control group maximum number $23(76.7 \%)$ of patient were in term ( $>37$ weeks) gestational age and the difference was statistically significant $(\mathrm{p}-<0.001)$ (Table-II). Similar type of result was found in the study done by Chanvitya Punthumapol and Boonsri Kititchotpanich, in which they found that normal pregnant women had mean gestational age more than both mild and severe preeclamptic women significantly. $(38.3 \pm 1.97$ weeks vs. $36.31 \pm 3.2$ weeks, $\mathrm{p}=0.035$; and $36.24 \pm 3.58$ weeks, $\mathrm{p}=0.03$ respectively) $)^{13}$.

In this study primi patient were $13(43 \%)$ in case and $11(36.7 \%)$ in control group, multi patient were $17(56.7 \%)$ in case and $19(63.3 \%)$ were in control group, data was statistically not significant ( $\mathrm{p}>0.598)$ (Table-III). This finding is not consistent with the findings of Dutta, in which he has found the incidence of pre-eclampsia in primigravida is about 10 percent and in multigravida is $5 \%{ }^{7}$. This finding may be due to small sample size and data were collected randomly.

An elevated systolic and diastolic blood pressure was found in case and control group. Systolic and diastolic blood pressure were significantly high among cases in comparison to control group ( $<<0.001)$ (Table-IV). This is consistent with the findings of Roburts and Redman, in which they have found in preeclampsia that there will be rise of blood pressure of $>15 \mathrm{~mm}$ of $\mathrm{Hg}$ diastolic and $>30 \mathrm{~mm}$ of $\mathrm{Hg}$ systolic from measurement in early pregnancy or to $>140 / 90 \mathrm{mmHg}$ in late pregnancy if no early reading is available ${ }^{3}$.

The main objective of the study was to find out the level of serum calcium in preeclamptic and normotensive women. In this study serum calcium level was found to be significantly low in pre-eclampsia than that of control pregnant women. In this study mean serum calcium level found $7.88 \pm 0.75 \mathrm{mg} / \mathrm{dl}$ in cases and $9.9267 \pm 0.58 \mathrm{mg} / \mathrm{dl}$ in control group (table-XII). This is consistent with the findings of Hojo and Augast, in which they have found that calcium deficiency, is associated with preeclampsia. ${ }^{14}$

Another study identified the serum calcium level reduced in preeclamptic women $(8.70 \pm 0.59) \mathrm{mg} / \mathrm{dl}$ then that of normotensive pregnant women ${ }^{15}$. The data supported the hypothesis that calcium might be a cause in the development of pre-eclampsia.
The effect of serum calcium on changes in blood pressure could be explained by the increased level of intracellular concentration of calcium. The level of free intracellular calcium is a major determinant of vascular smooth muscle tone and consequently resistance, Thus increase of intracellular calcium concentration causes constriction of smooth muscle in blood vessels and increase vascular resistance. There by increase blood pressure $^{15}$.

Another similar study is identified which was done by Naser $\mathrm{O}$. Malas, they have explained calcium is one of the most abundant elements in the human body and serve as a variety of vital function $^{15}$. Pregnancy entails a number of physiologic events with implications regarding calcium metabolism, the extracellular fluid expands, the albumin level decreases. The glomerular filtration rate increase causing increase in calciuria and calcium is removed from the maternal system by transfer to the fetus. This mechanism all tend to propose lowering of maternal calcium concentration. Potkin RM et al, identified that calcium supplemented group showed reduced incidence of pre-eclampsia than that of placebo group ${ }^{16}$.

\section{CONCLUSION}

The development of pre-eclampsia is high in developing countries like Bangladesh where antenatal care is inadequate. Since this complication is mostly preventable in large number of cases detected and treated at an early stage, it is eventual to detect the condition at an early stage and to provide adequate antenatal care in due time.

Determination of serum calcium which is very simple to analyze may be used to detect pre-eclampsia in addition to the other sign of pre-eclampsia like proteinuria and hypertension. In numerous controlled trials, oral calcium supplementation has been studied as a possible preventive measure while most trial have found significant reduction in the incidence of preeclampsia with calcium supplementation although some have reported no change.

Regardless of the mechanism and pathophysiology, hypocalcaemia may be a reliable finding of pre-eclampsia from other forms of gestational hypertension.

\section{DISCLOSURE}

All the authors declared no competing interest. 


\section{REFERENCES}

1. Asnat Walfisch, Mordechai Hallak. Hypertension. In: High Risk Pregnancy Management Option. D. K. James \& P. J. Steer, editors $3^{\text {rd }}$ ed. Elsevier. 2006;772-797.

2. David A. Miller. Hypertension in Pregnancy. In: Current Obsteritical and Gynaecological Diagnosis \& Treatment. Decherney AH \& Lauren Nathan, editors $10^{\text {th }}$ ed. The McGrao-Hill Companies USA. 2007; 321-327.

3. Roberts JM, Redman CWG. Pre-eclampsia: More than pregnancy-induced hypertension. Lancet. 1993; 341:1447-1448.

4. Roberts JM, Taylor RN, Musci TJ, Rodgers GM, Hubel CA, McLaughlin MK. Preeclampsia: an endothelial cell disorder. Am J Obstet Gynecol. 1989; 161:1200-1204.

5. Cunningham FG, Leveno KJ, Bloom SL, Hault JC, Gilstrap LCIII, Wenstrom KD. Williams obstetrics. $22^{\text {nd }}$ ed. New York: McGraw-Hill. 2005;761-808.

6. Keith JC Jr, Miller K, Eggleston MK, Kutruff J, Howerton T, Konezal C et al. Effects of thromboxane synthatase inhibition on maternalfetal homeostasis in gravid ewes with ovine pregnancy -induced hypertension. Am J Obstet Gynecol. 1989;161:1305-1313.

7. Dutta Dc. Hypertensive disorder in pregnancy. In : Textbook of obstetrics. $7^{\text {th }}$ ed. Calcutta: New Central Book Agency(P)Ltd. 2005;221-242.

8. Fauvcau V, Kochning MA. And Chakrobarty J. Causes of Maternal mortalityin rural Bangladesh; Bulletin of WHO. 1988;66: 643-651.

9. Chesley L. National High Blood Pressure Education program working group report on high blood pressure in pregnancy. Am J Obstet Gynecol. 1990;163: 1697.

10. Pitkin RM. Calcium metabolism in pregnancy. Am J Obstet Gynecol. 1975;121:724-737.

11. Allen I, Oddoye EA, Morgen S. Protein induced hypercalcemia: A longer term study. Am J Clin Nutr. 1979; 32: 741-749.

12. Duckitt K. Harrington D. Risk features for Preeclampsia at antenatal booking: Systemic review of controlled studies. Br. Med J. 2005; 330: 565-568.

13. Chanvitya Punthumapal, Boonsri kititchotpanich. Serum Calcium, magnasium and uric acid in Pre-eclampsia and normal pregnancy. J med Assoc Thai. 2008; 91(7): 968-973.

14. Hoji M, Auust P. Calcium metabolism in normal and hypertensive pregnancy. Semin Nephrol. 1995; 15: 504-505.

15. Naser O. Malas, Ziad M Shurideh. Does serum calcium in Pre-eclampsia and normal pregnancy differ. Saudi Med J. 2001;22(10):868-871.

16. Potkin RM, Reynolds WA, Williams GA, Hargis GK. Calcium metabolism in normal pregnancy. A longitudinal study. AM J Obstet Gynaecol. 1979;133: 781-790. 